\title{
ERgONOMIC WORKPLACE DESIGN IN THE Clothing ShoP
}

\author{
VUJICA H. N. \& BUCHMEISTER, B.
}

Abstract: Introducing ergonomic principle into work is very important. Since work is one of the basic factors of human life appropriate designed workplace can contribute to healthy and satisfied worker. Beside that ergonomically designed workplace also improves worker's efficiency at work and decreases the possibility of injuries. The aim of the presented research was to determine whether the work area within a chosen retail shop was safe and effective enough. The OWAS method was used aimed to estimate the body postures during the working day. It was discovered that certain body positions resulted in significant overload which meant that certain remedies were necessary during the working process to prevent possible damage to the body. As a result an innovative system with moving shelves was proposed in order to prevent the shopkeeper from awkward body postures. Similar solutions can be found in industrial warehouses and could solve problems that occur during overhead work.

Key words: ergonomics, anthropometry, OWAS, strain and stress at work, workplace design
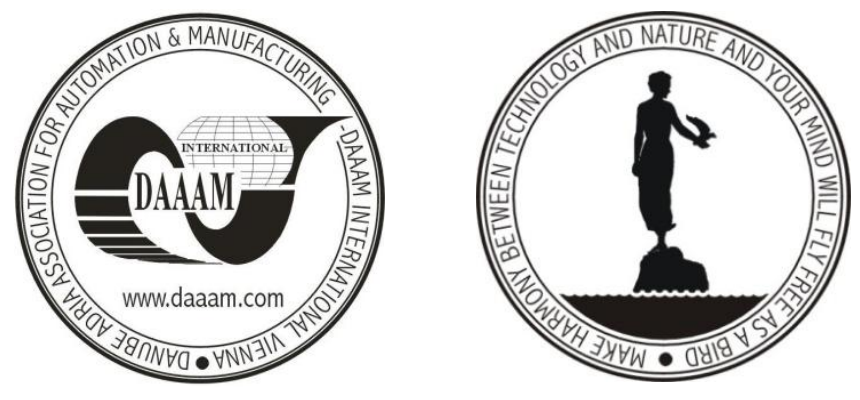

Authors' data: Asist. Prof. Dr. Sc. Vujica Herzog, N[atasa], Assoc. Prof. Dr. Sc. Buchmeister, B[orut]; University of Maribor, Faculty of Mechanical Engineering, Smetanova ulica 17, 2000, Maribor, Slovenia, natasa.vujica@um.si, borut.buchmeiste@um.si

This Publication has to be referred as: Vujica Herzog, N[atasa] \& Buchmeister, B [orut] (2014). Ergonomic Workplace Design in the Clothing Shop, Chapter 08 in DAAAM International Scientific Book 2014, pp.109-120, B. Katalinic (Ed.), Published by DAAAM International, ISBN 978-3-901509-98-8, ISSN 1726-9687, Vienna, Austria

DOI: $10.2507 /$ daaam.scibook.2014.08 
Vujica Herzog, N. \& Buchmeister, B.: Ergonomic Workplace Design in the Cloth...

\section{Introduction}

For successful workplace design several elements must be examined: space, equipment, tools, auxiliary devices, etc. Of decisive importance for healthy and enjoyable jobs is a neat and organized workplace that must be sufficiently spacious, airy, bright, and comfortable. Lighting is of significant importance as it provides contrast between the working and surrounding areas. Lighting should shed enough light yet should not adversely affect the sight of the user. On the other hand, its noise should not disturb composure and communication. The workplace's size and shape must therefore be adapted to a human's working activities to allow him/her as many comfortable working postures as possible.

In addition, safety within the workplace must be ensured whilst working in order to preserve the health of the worker. Working systems differ from each other but what they have in common is that they are formed as a result of conscientious, systematic, and creative human efforts.

The purpose of this research work was to point out that a well-ordered workplace provides a pleasant atmosphere that at the same time encourages greater productivity from the worker. In this way it is possible to achieve an enjoyable workplace for the worker with minimum body stress, which may affect his/her physical and mental ability to work. The aim of the presented research work was therefore to conclude whether the chosen workplace was effective enough, and if potential changes to that workplace were needed or possible.

Using the current observation method it can be evaluated whether certain parts of the body are experiencing too much stress, which means that necessary actions are needed in order to reduce the body's overload. Namely, stresses on certain parts of the body reduce a human's ability to be effective while working. Therefore it is very important that the workplace, in the textile industry also, is optimized in such a way that e.g. desks, chairs, and appliances are constructed and installed well, in order to prevent bad positions of the human's body.

Ergonomics deals with the exploration of human physical and mental capabilities during working and adjusting the working load. By using ergonomic arrangement of the workplace it is possible to adapt work to a human's physical and mental characteristics and to reduce or prevent adverse effects on health. Correct designing of the workplace also includes human habits to ensure humans' work as productively effectively, and safely as possible.

The two most important factors that influence stress at work can be divided into:

- Working environments with working conditions such as noise, heat, humidity, illumination, air velocity and

- Body postures; especially awkward postures that can cause health problems. The OWAS observation method can be used for posture analyses. 


\section{Literature review}

Work-related musculoskeletal disorders have been increasing within manufacturing and services. As these injuries impose high costs for companies (worker absence, manufacturing losses, delays...) and society (high costs of medical treatment), it is important to prevent them through ergonomic assessment and job redesigning.

One of the more significant contributory factors of neck and shoulder pains is when working with arms above shoulder height, which is referred to as 'overhead work' (Aghazadeh et al., 2012; Grieve \& Dickersond, 2008; Garg et al., 2006; Nussbaum et al., 2001; Spyropoulus et al., 2013). Overhead work can be found within various occupations and industries such as healthcare, nursing, automobile manufacturing, mining, welding and maintenance/repair work (Rosecrance et al., 2006; Harcombe et al., 2006; Warming et al., 2009). Workers in these occupations suffer from neck and shoulder pains, discomfort, and limited productivity. Aghazadeh and other authors (2012) studied the effect of overhead lifting on neck and shoulder muscle activities and upper extremity joint angles. They quantified the relationships between the upper extremity joint angles and neck muscle activity during overhead lifting. The results showed that shoulder angles had a significant influence on neck muscle activity; this was because as the shoulder angles increased, the neck muscle activity also increased. The results indicated that lifting with elevated arms should be avoided, especially when heavy weights are being lifted.

Various strains and stresses reduce human efficiency at work due to disturbed haemostasis, thus resulting in fatigue. In order to reduce the effects of this phenomenon, working hours should be interrupted by several rest periods and breaks (Nussbaum et al., 2001; Spyropoulus et al., 2013). In addition the workplace should be designed using anthropometric measures, in regard to human dimensions (Polajnar et al., 2010).

\section{Methodology}

The following steps were taken for considering the presented problem.

- Workplace analysis and evaluation; analysis of the existent workstation dimensions with respect to working postures and workers' perceptions; the saleswoman in a store 7' Camicie observation. The observation was conducted over two days, 3 hours per day, 6 working-hours altogether.

- Workplace analysis by considering the working environment; accurate measurements were taken of noise, illumination, heat, humidity, and air velocity.

- The extended OWAS method was used at nursing workstations to evaluate the strains caused by different operators' postures. 
Vujica Herzog, N. \& Buchmeister, B.: Ergonomic Workplace Design in the Cloth...

- The examined workplace was designed and analysed using the Jack software package created by Technomatics.

- Comparison between manually-performed OWAS analysis and software OWAS analysis was made to confirm the reliability of the performed research,

- Based on the results of OWAS analysis certain propositions were advanced for improving working conditions and preventing possible health problems in the future.

\section{Workplace observation}

\subsection{Clothing shop 7 ' Camicie}

7 ' Camicie is a recognized Italian clothing brand known for its glamour, quality, and versatility. It is suitable for men who love elegance, as well as for women who like to display their ambitions (Fig. 1).

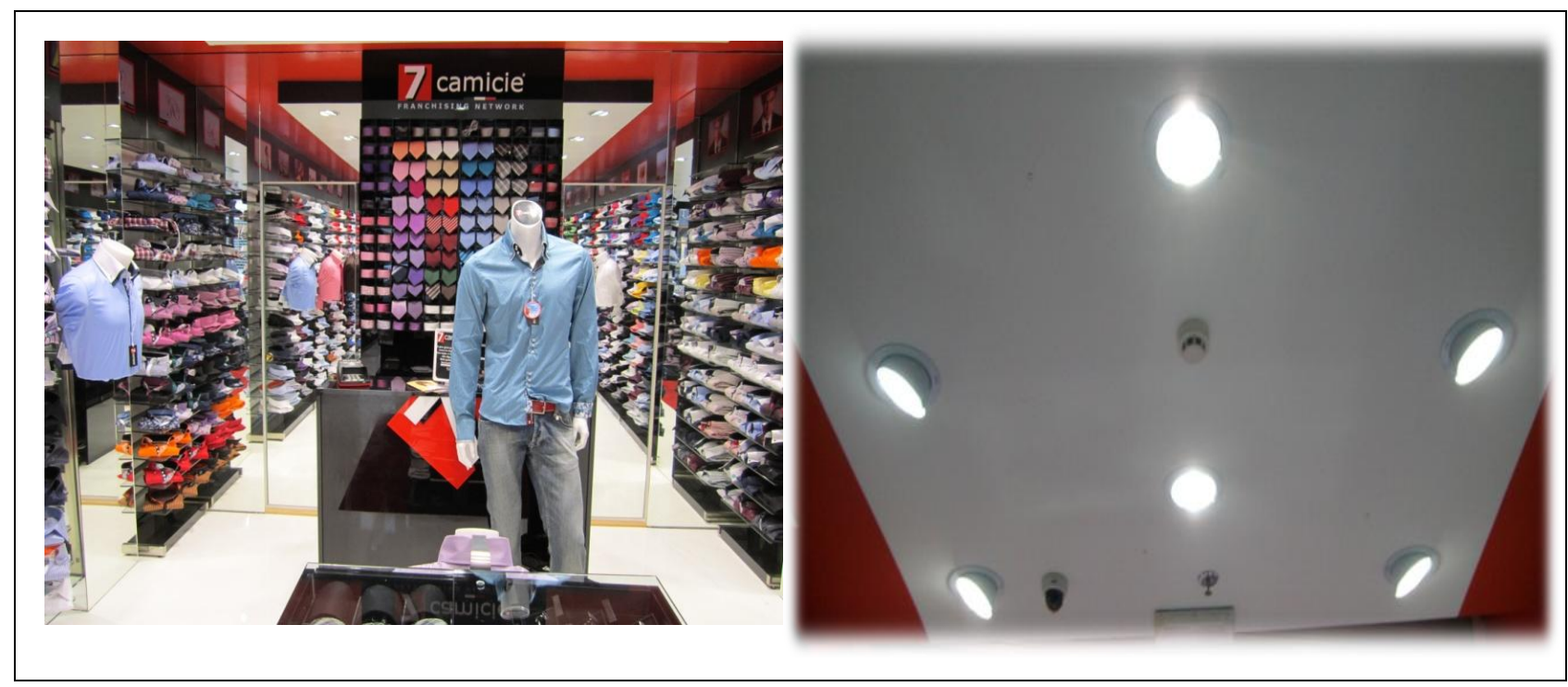

Fig. 1. 7 ' Camicie shop

Fig. 2. 7 ' Camicie shop's lighting

As is seen from (Fig. 2) the shop is equipped with general lighting. The saleswoman performed mainly standing work (Fig. 3). Whilst loading the material onto shelves or taking them down for the customers she uses a ladder. The posture position is dangerous as the saleswoman must remain on the ladder and reach-up for the desired piece with one or both arms above her shoulder. Ladders must be used securely so that they cannot slip, be tipped-over or malfunction. When the ladder is used, the woman must stand with both feet on the same rung of the ladder (Fig. 4).

Microclimatic parameters are important factors in the physical environment which significantly affect the conditions of the working environment (Andrejiova et al., 2012). These parameters significantly affect the welfare of working people and should be verified regularly. Two different measuring devices were used during the experiment. The noise was measured using Voltcraft SL-100 noise-meter (Fig. 5 - a). 
Other measurements such as illumination, heat and air velocity were taken using the Testo 435 multifunctional device (Fig. 5 - b).

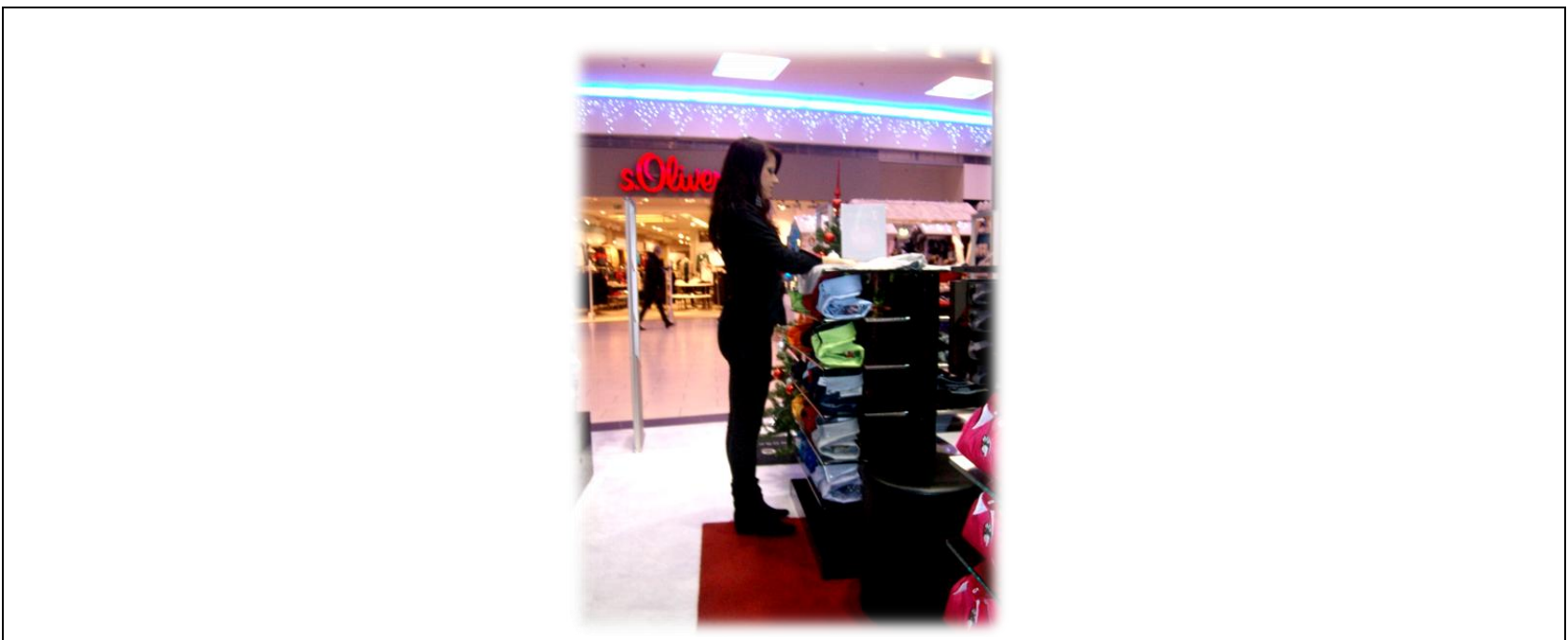

Fig. 3. The prevalent working position
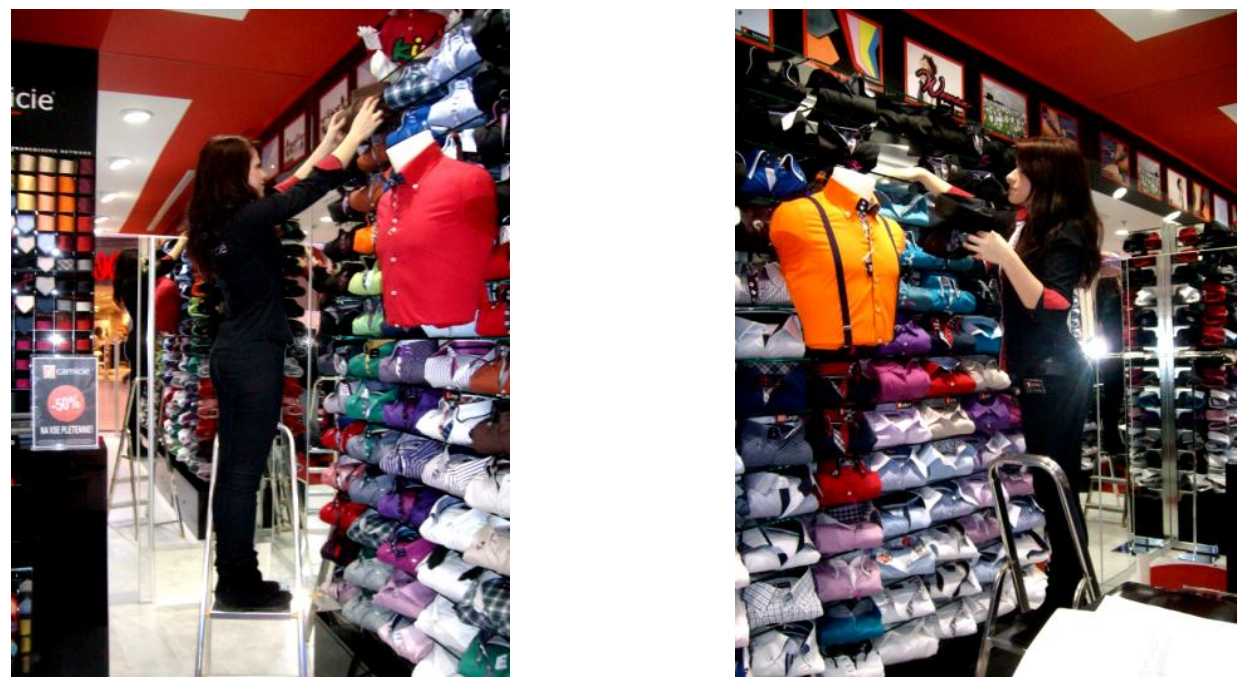

Fig. 4. Uploading the material onto the shelves with the help of a ladder

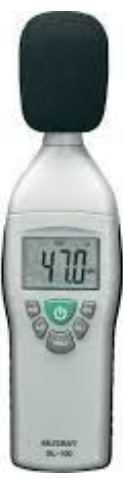

a.

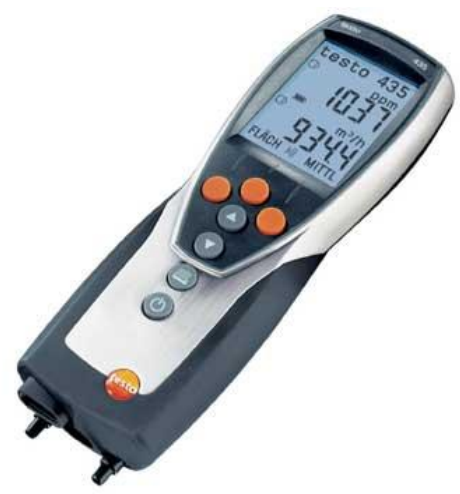

b. 


\subsection{OWAS method}

The OWAS method (Ovaco Working Analysing System) is a method of posture monitoring. This method originated from Finland's steel industry where body the positions of workers were analyzed using an elaboration observation method called OWAS. This method was initially successful and was therefore further developed and modified. It is considered to be a practical method for identifying and evaluating working postures. The OWAS procedure consists of two parts: an observational technique for classifying body postures, and a set of criteria for the redesigning of working methods and workplaces. Body postures are classified into 28 positions including the positions of the back (four positions), upper limbs (four), hands (three), lower limbs (nine), head and neck (five), as well as the load or force handled (three).

Each of these positions has pre-defined high risk and low risk postures that are coded by the observer. After calculating the amount of time the worker maintains these postures, the final step is to assign a four-level action code for task improvement. These four action codes are defined as follows: changes are not needed, changes needed in near future, changes needed immediately, need intensive observation.

\subsection{Computer-Aided OWAS analysis}

In order to asses the presented workplace the ergonomic software package Jack was used, as created by Siemens PLM. Jack is a complete system for generating 3D environments and interacting with them within a powerful graphical environment. It is based on a detailed link segment model with biologically accurate motion prediction and joint kinematics. When using Jack we can design real-time environment with interactive viewing, multiple windows, lights and cameras, textures, and mirrors.

The most important and useful part of Jack software is the possibility of performing different analyses. The Jack analysis toolkit is a set of Ergonomic analysis tools that help us to design better work areas and evaluate physical tasks. Some of the analyses are:

- Lower back analysis tool,

- Static Strength prediction,

- NIOSH,

- Metabolic energy expenditure,

- Fatigue recovery,

- Ovako Working Posture Analysis (OWAS) tool,

- Rapid Upper Limb Assessment (RULA),

- Manual handling limits,

- Force solver,

- Predetermined time.

By using different analyses Jack enables us to design a workplace that minimises the risk of low back injuries, determines whether workers have enough strength to perform their prescribed job,, design and evaluate lifting jobs, determine 
the metabolic energy requirements of a job and compare alternative job designs based on their relative risks of exposing workers to fatigue. In addition Jack help us when assessing working postures for their potentials to expose workers to injury, identify manual tasks that expose workers to increased risk of upper limb disorders, evaluate manual handling tasks and predict whether a worker can be expected to perform a job under predefined cyclical-time requirements.

We used Jack 7.0 for redesigning the workplace in 7 Camices' shop by simulating working postures and above all to perform several analyses.

\section{Workplace analyses and results}

During the workplace analyses when considering working environment, accurate measurements were taken of noise, illumination, heat, and air velocity, (Tab. 1). The measured values of temperature and air velocity were suitable for the presented working environment. The noise level was also within the recommended values. Space illumination was very high and the illumination effect was even higher because of mirrors fitted onto the walls and therefore the illumination was magnified. It is generally known from research performed within manufacturing that higher illumination levels increase productivity and increase attentiveness that could also be of benefit in a clothes shop.

\begin{tabular}{|l|c|c|c|c|}
\hline \multirow{5}{*}{} & \multicolumn{3}{|l|}{ Measured values } \\
\cline { 2 - 5 } & $\begin{array}{c}\text { Noise } \\
{[\mathrm{dB}]}\end{array}$ & $\begin{array}{c}\text { Illumination } \\
{[1 \mathrm{x}]}\end{array}$ & Temp. $\left[{ }^{\circ} \mathrm{C}\right]$ & Air velocity $\left[\mathrm{ms}^{-1}\right]$ \\
\cline { 2 - 5 } & 63 & 1530 & 22.5 & 0.09 \\
\cline { 2 - 5 } & 72 & 1520 & 23.2 & 0.14 \\
\cline { 2 - 5 } & 59 & 1490 & 22.3 & 0.11 \\
\hline Average value & 64.6 & 1513.3 & 22.7 & 0.11 \\
\hline
\end{tabular}

Tab. 1. Noise level, illumination, temperature, and air velocity

When observing the working postures, the OWAS method was conducted over two days, for 3 hours each day, altogether 6 working hours. In the Tables below (Tab. 2 and Fig. 7) the results of the body position monitoring can be seen. $248(\mathrm{n}=248)$ measurements were performed during 6 hours of working; approximately one record per minute. The method of working was similar across the entire workday, so it can be assumed that all possible positions that could be harmful for the worker were observed and recorded.

Prior to starting the observation procedure we followed the worker and her body positions. The results from our observations were recorded by drawing lines on a particular form. On this basis we calculated the share of each physical situation and the time of each body position. The calculations required the following information: the sum of each body position $\left(\sum \mathrm{F}_{\mathrm{p}}\right)$, and the sum of all body positions within each 
group of working positions $\left(\sum \mathrm{F}_{\mathrm{s}}\right)$. Equation 1 was used for calculating each body posture.

$$
p=\frac{\sum F p \cdot 100}{\sum F S}[\%]
$$

Duration of a particular body position $\left(t_{p}\right)$ was calculated using Equation 2:

$$
t_{p}=\frac{450 \cdot p}{100}[\mathrm{~min}]
$$

The obtained results were compared with the recommended measurements (Tab. 3 ) and the results are presented with signs in Tab. 2 and in the histogram (Fig. 7). As can be deduced from the results and histogram where the allowed and recommended values were recorded, there were overloads in the following body positions: $1.2-$ bent back, 2.3 - one arm above shoulder, 2.4 - both arms above shoulders, $4.3-$ standing on one leg, 5.2 - bent forward head and neck, 5.3 - bent to side head and neck and 5.4 - bent backwards head and neck. According to OWAS positions

\begin{tabular}{|c|c|c|c|c|c|c|c|c|c|c|c|c|c|c|c|c|c|c|}
\hline \multirow{3}{*}{$\begin{array}{l}\text { Body } \\
\text { Parts }\end{array}$} & \multicolumn{3}{|c|}{$\begin{array}{c}\text { Thoraxlumb. } \\
\text { spine }\end{array}$} & \multicolumn{4}{|c|}{ Upper limb } & \multicolumn{3}{|c|}{ Hands } & \multicolumn{3}{|c|}{ Lower limb } & \multicolumn{5}{|c|}{ Head } \\
\hline & 1.1 & 1.2 & 1.3 & 2.1 & 2.2 & 2.3 & 2.4 & 3.1 & 3.2 & 3.3 & 4.2 & 4.3 & 4.6 & 5.1 & 5.2 & 5.3 & 5.4 & 5.5 \\
\hline & & ¿ & i & 京 & 요 & $\cdot 9$ & $\uparrow$ & $\triangle$ & $\Lambda$ & $\angle$ & I & is & a. & 9 & $V^{8}$ & 1. & 9 & b. \\
\hline $\begin{array}{l}\text { Nr. of } \\
\text { measur. }\end{array}$ & 110 & 90 & 48 & 78 & 30 & 80 & 60 & 108 & 72 & 42 & 100 & 82 & 66 & 80 & 58 & 52 & 58 & 40 \\
\hline$p_{i}[\%]$ & 40.3 & 36.3 & 19.3 & 31.5 & 12.1 & 32.2 & 24.2 & 48.6 & 32.4 & 18.9 & 40.3 & 33.0 & 26.6 & 32.2 & 23.4 & 20.9 & 23.4 & 11.1 \\
\hline$t_{p i}[\mathrm{~min}]$ & 145.1 & 130.7 & 69.5 & $\overline{113.4}$ & 43.6 & 115.9 & 887.1 & 175 & 116.6 & 68.0 & 145.1 & 118.8 & 95.8 & 115.9 & 84.2 & 75.2 & 84.2 & 40 \\
\hline Measure & 口 & - & 口 & 口 & $\square$ & - & - & 口 & $\square$ & $\square$ & 口 & - & 口 & 口 & $\bullet$ & - & - & $\square$ \\
\hline
\end{tabular}
changes were needed for these positions in the near future.

Tab. 2. OWAS - calculated results with recommended measures

\subsection{Comparison with the computer performed OWAS method}

Since manually performed OWAS method is time consuming and can be annoying for a worker we decided to design and analyze workplace also using computer simulations and analyses.

The results from computer-aided posture simulations confirmed the posture problems discovered using the manually performed OWAS method. In regard to those body postures of bent back, one arm above shoulder, both arms above shoulder, standing on one leg, and all head positional changes were needed in the near future. 


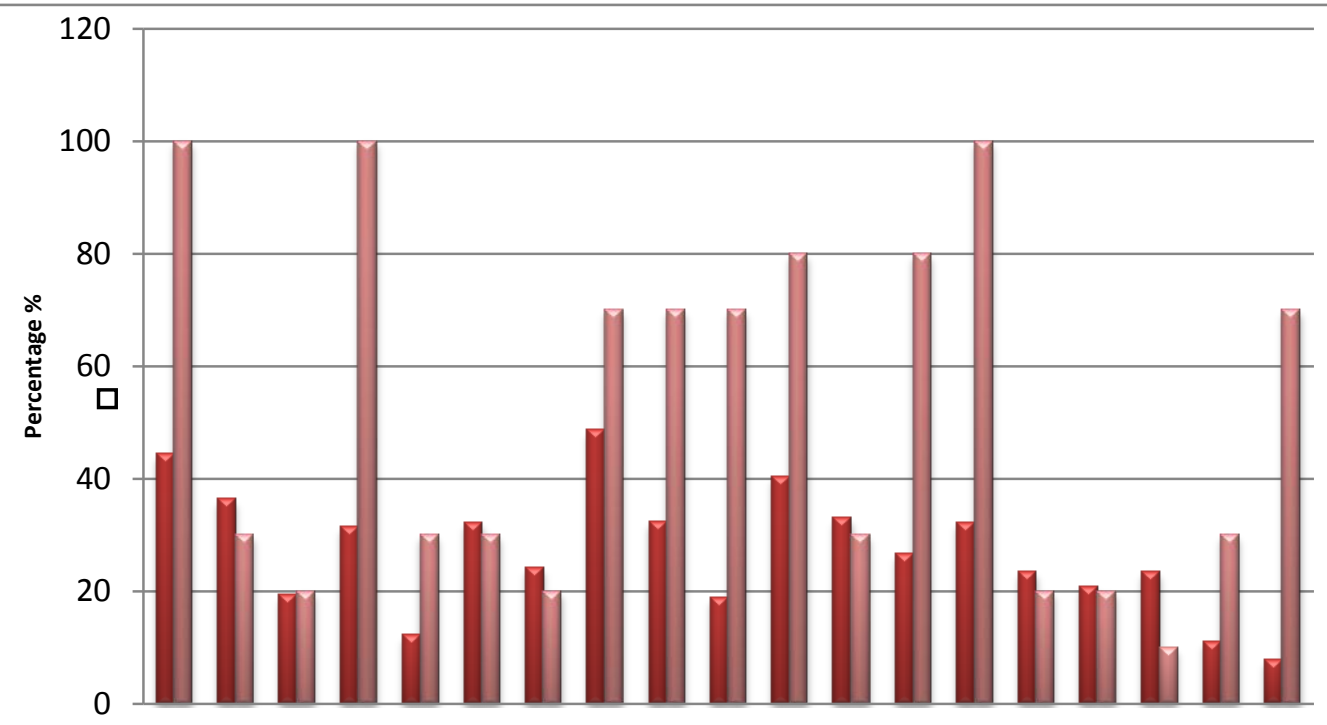

Measured

Allowed

1.1. 1.2. 1.3. 2.1. 2.2. 2.3. 2.4. 3.1. 3.2. 3.3. 4.2. 4.3. 4.6. 5.1. 5.2. 5.3. 5.4. 5.5. 6.1 .

Body postures

Fig. 7. The histogram of the OWAS results applied at the inspected workplace

\begin{tabular}{|c|c|c|c|c|c|c|c|c|c|c|c|c|c|c|c|c|c|c|c|}
\hline $\begin{array}{l}\text { Body } \\
\text { Parts }\end{array}$ & \multicolumn{4}{|c|}{$\begin{array}{l}\text { Thoraxlumbal } \\
\text { spine }\end{array}$} & \multicolumn{4}{|c|}{ Upper limb } & \multicolumn{3}{|c|}{ Hands } & \multicolumn{3}{|c|}{ Lower limb } & \multicolumn{5}{|c|}{ Head } \\
\hline & 1.1 & 1.2 & 1.3 & 1.4 & 2.1 & 2.2 & 2.3 & 2.4 & 3.1 & 3.2 & 3.3 & 4.2 & 4.3 & 4.6 & 5.1 & 5.2 & 5.3 & 5.4 & 5.5 \\
\hline $\begin{array}{c}\text { OWAS } \\
\%\end{array}$ & L & i & . & 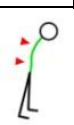 & 京 & 尔. & $\lambda$ & 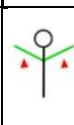 & $\Delta$ & $\Lambda$ & $\angle$ & 9 & 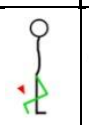 & ? & 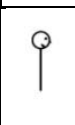 & 1. & $|\cdot|$ & $\stackrel{9}{*}$ & L \\
\hline 10 & $\square$ & 口 & 口 & $\bullet$ & $\square$ & $\square$ & $\square$ & $\square$ & 口 & $\square$ & $\square$ & $\square$ & $\square$ & $\square$ & $\square$ & $\square$ & $\square$ & $\square$ & $\square$ \\
\hline 20 & $\square$ & 口 & $\square$ & $\bullet$ & $\square$ & $\square$ & 口 & $\square$ & 口 & $\square$ & $\square$ & $\square$ & $\square$ & $\square$ & $\square$ & $\square$ & $\square$ & $\bullet$ & $\square$ \\
\hline 30 & $\square$ & $\square$ & $\bullet$ & $\bullet$ & $\square$ & $\bar{\square}$ & $\bar{\square}$ & $\bullet$ & 口 & $\bar{\square}$ & $\bar{\square}$ & $\square$ & $\bar{\square}$ & $\square$ & $\square$ & $\bullet$ & $\bullet$ & $\bullet$ & 口 \\
\hline 40 & 口 & $\bullet$ & $\bullet$ & $\bar{\Delta}$ & $\square$ & $\bullet$ & 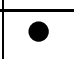 & $\bullet$ & $\bar{\square}$ & $\square$ & $\square$ & $\square$ & $\bullet$ & $\square$ & $\square$ & $\bullet$ & $\bullet$ & $\bar{\Delta}$ & $\bullet$ \\
\hline 50 & $\square$ & $\bullet$ & $\bullet$ & $\bar{\Delta}$ & $\square$ & $\bullet$ & 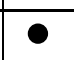 & - & $\square$ & $\square$ & $\square$ & $\square$ & $\bullet$ & 口 & $\bar{\square}$ & $\bullet$ & $\bullet$ & $\bar{\Delta}$ & - \\
\hline 60 & प & $\bullet$ & $\bar{\Delta}$ & $\bar{\Delta}$ & $\square$ & $\bullet$ & $\bullet$ & $\bullet$ & $\bar{\square}$ & $\square$ & $\square$ & D & $\bullet$ & $\square$ & $\square$ & $\Delta$ & $\bar{\Delta}$ & $\bar{\Delta}$ & $\bullet$ \\
\hline 70 & 口 & $\bullet$ & $\bar{\Delta}$ & $\bar{\Delta}$ & $\bar{\square}$ & $\bullet$ & $\bullet$ & $\bar{\Delta}$ & $\square$ & $\square$ & $\square$ & $\square$ & $\bullet$ & $\square$ & $\square$ & $\bar{\Delta}$ & $\bar{\Delta}$ & $\bar{\Delta}$ & $\bullet$ \\
\hline 80 & $\square$ & $\bar{\Delta}$ & $\Delta$ & $\Delta$ & $\square$ & $\Delta$ & $\Delta$ & $\Delta$ & $\star$ & $\star$ & $\star$ & 口 & $\Delta$ & $\bar{a}$ & $\square$ & $\bar{\Delta}$ & $\bar{\Delta}$ & $\bar{\Delta}$ & $\Delta$ \\
\hline 90 & $\square$ & $\Delta$ & $\Delta$ & $\Delta$ & $\square$ & $\Delta$ & $\bar{\Delta}$ & $\Delta$ & $\star$ & $\star$ & $\star$ & $\bullet$ & $\bar{\Delta}$ & $\bullet$ & 口 & $\bar{\Delta}$ & $\bar{\Delta}$ & $\bar{\Delta}$ & $\bar{\Delta}$ \\
\hline 100 & 口 & $\Delta$ & $\bar{\Delta}$ & $\bar{\Delta}$ & $\square$ & $\bar{\Delta}$ & $\bar{\Delta}$ & $\Delta$ & $\star$ & $\star$ & $\star$ & $\bullet$ & $\bar{\Delta}$ & 0 & $\square$ & $\Delta$ & $\Delta$ & $\bar{\Delta}$ & $\Delta$ \\
\hline
\end{tabular}

Legend for Table 3:

$\square \quad$ - changes are not needed

- - changes needed in near future
$\Delta$ - changes needed immediately

$\star$ - needed intensive observation

Tab. 3. OWAS - review table of recommended measures

An example of simulation for the saleswoman's movements when taking the shirt from the shelf is shown in Fig. 8 with the detailed results of OWAS analyses on the right. Body posture 'both arms above shoulder' is signed with yellow which means that changes are needed in the near future and the message is written: 'The work posture may have harmful effects on the musculoskeletal system.' 
Vujica Herzog, N. \& Buchmeister, B.: Ergonomic Workplace Design in the Cloth...
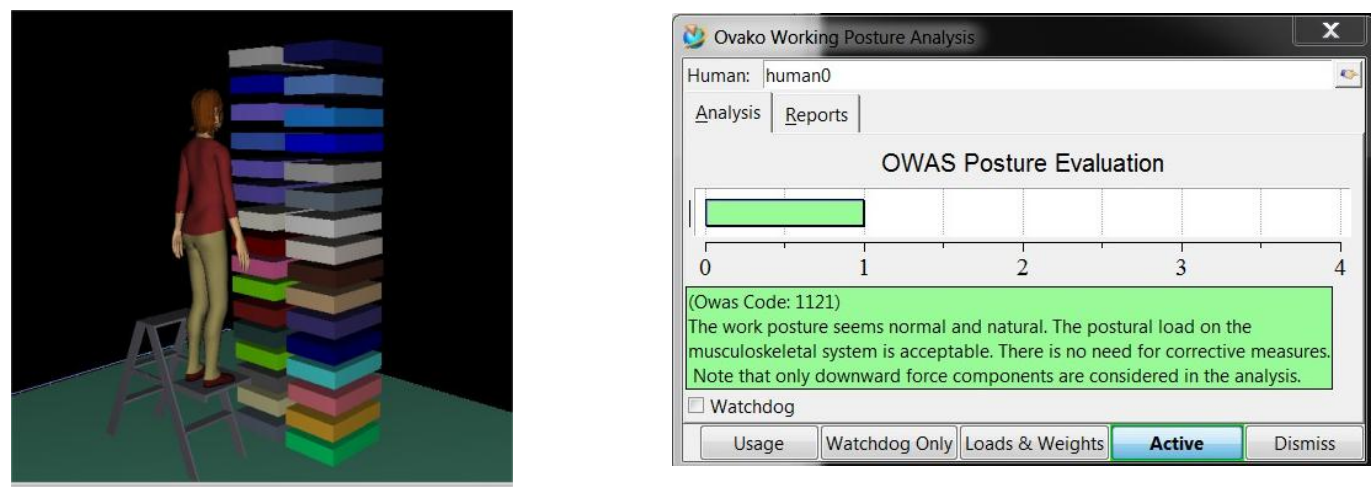

a. Both arms near body - normal position
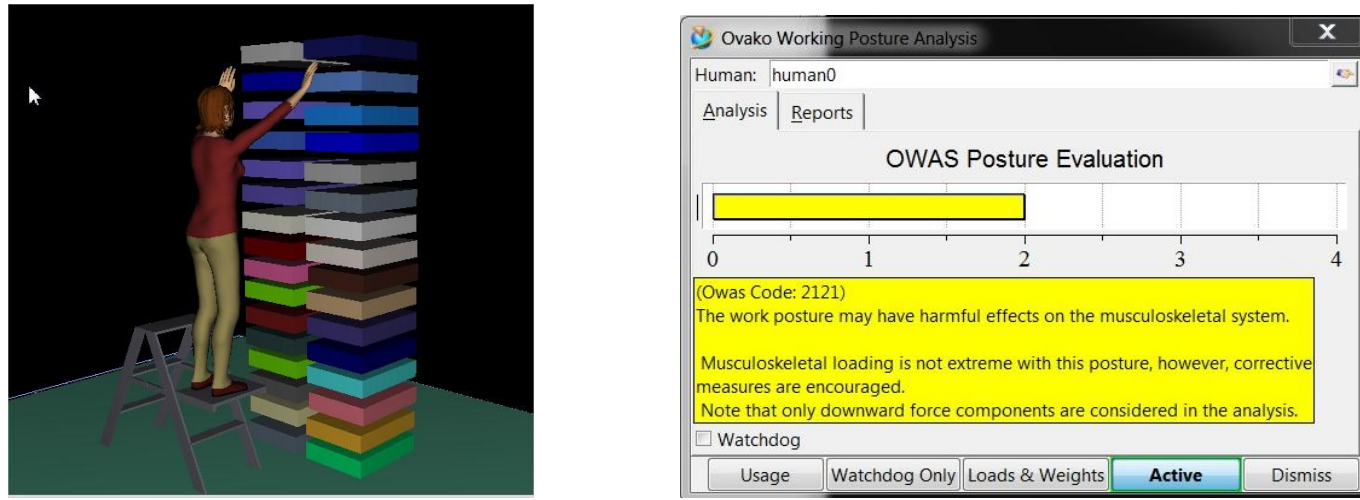

b. Both arms above shoulder - the posture may have harmful effects
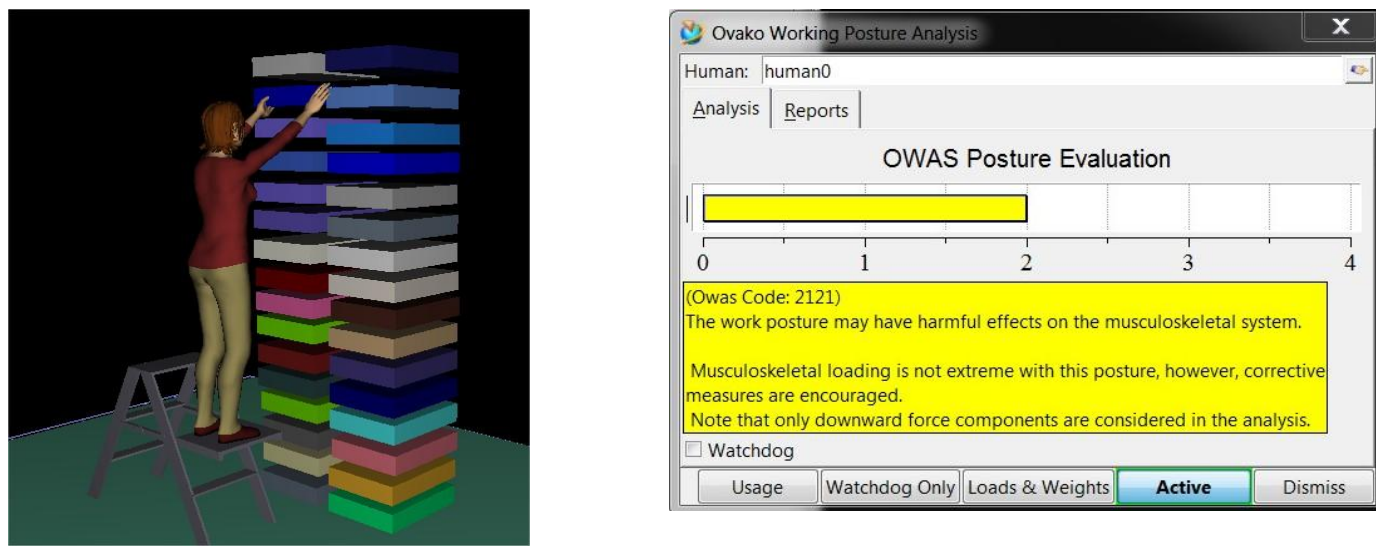

c. Both arms above shoulder - the posture may have harmful effects

Fig. 8. Computer aided performed OWAS analysis

\section{Proposal for working positions' improvements}

Following the results from the OWAS method some changes needed to be made in the near future. The greater problems are those shelves placed relatively high and therefore the reaching of pieces at higher places is impossible without a ladder. In spite of that some solutions are possible but by greater effort and changes. Different solutions for high shelves exist within manufacturing that could also be used within the clothing shop. The idea of a movable shelves system within or without a wardrobe is one of them. The working principle is shown in Fig. 9. Shirts and 
chemise could be put on shelves fixed within the movable system. In that way the saleswoman could stop the system when the desired shirt or chemise moves passed and could then take it from the shelf without uncomfortable body positions.

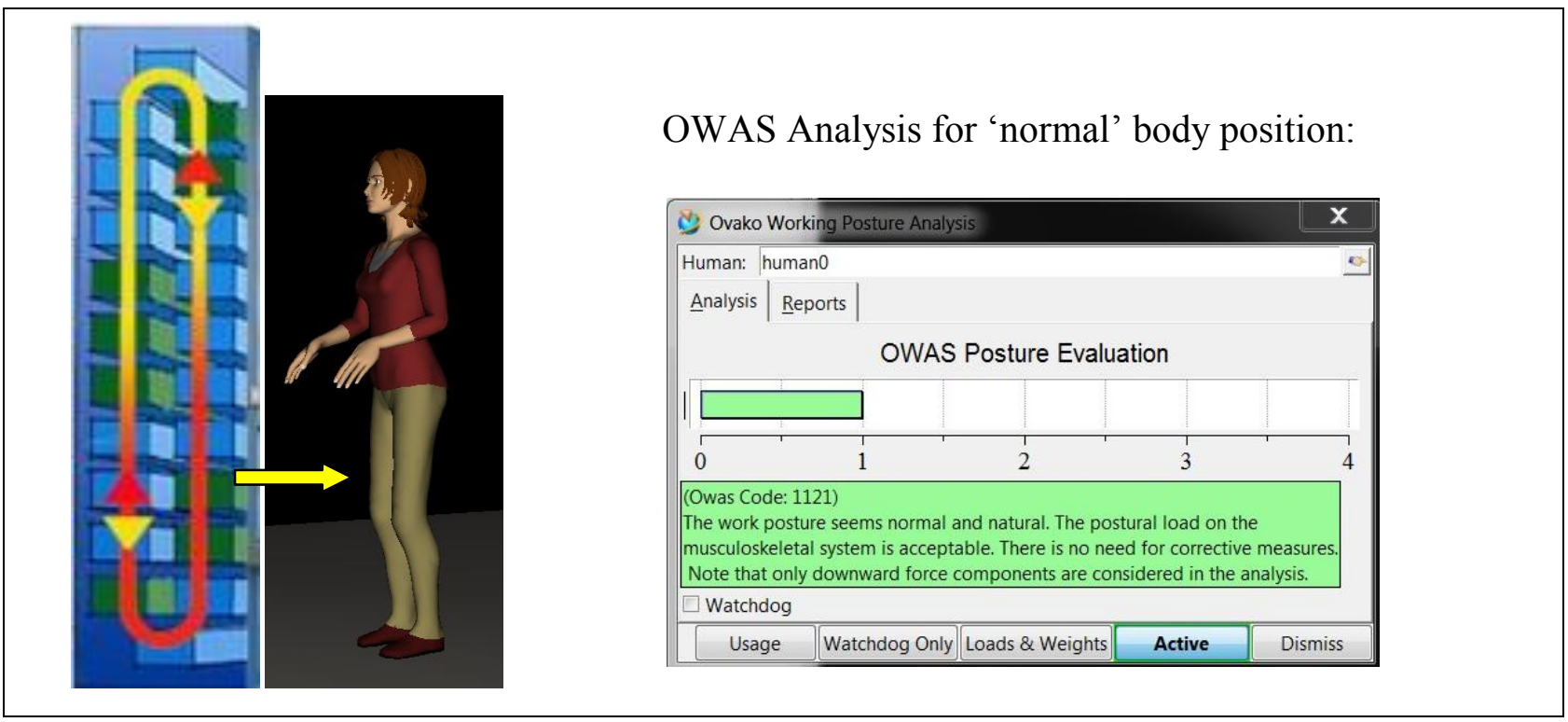

Fig. 9. The principle of the moving shelves system in clothing shop

\section{Conclusions}

Poorly designed workplace may have long-term negative consequences which, from the perspective of the employer, are reflected in diminished sales power and from the perspectives of the employees in workers' health difficulties (e.g. spine damages, eye problems, etc.). It is very important from this point of view as to how a workplace is designed and organized.

In the paper the working environment within clothing shop was researched with the focus on a well-ordered workplace, which in accordance with the principles of ergonomics must be adapted to a human's physical and mental needs at a minimum effect on his/her health.

Regarding results of the OWAS observational method we concluded that work on the observed workplace was moderately difficult, as is evident from the analyses of postures and from the corresponding histogram. The admissible limits of the monitored saleswoman were exceeded at five positions, and actions were needed within reasonable time, which meant that in the future some changes would be needed. The similar results were gained also using computer aided simulation.

During the saleswoman's work the real layout of working desks, shelves, lighting, and positions of a particular shop were compared to the recommended positions of the body. It was concluded that in the shop the layout of the workingcounters was appropriate, whilst some shelves were placed either too low or too high. The greater problems were those shelves placed relatively high and therefore reaching pieces in higher places was impossible without a ladder. To prevent the worker from awkward body postures an innovative system with moving shelves was proposed. This solution would be a transfer from the industrial environment where 
warehouses with moving shelves are used when overhead work is necessary. The presented solution would, of course, have to be adjusted and designed for the clothes shop environment.

Workplace analysis considering working environment show that measured values of noise, temperature and air velocity are within recommended values except illumination where the measurements showed that the lighting was very high but this could be considered as a measure for raising the atmosphere ambience within the shop. When measuring a shirt it is also important to have suitable lighting for better judgment regarding the shirt's color and suitability.

\section{References}

Aghazadeh, F.; Mokrani, M.; Al-Qaisi, S.; Ikuma, L. \& Hassa, M. (2011/2012). Effect of overhead lifting on neck and shoulder muscle activity and upper extremity joint angles. Occupational Ergonomics, Vol. 10, pp. 165 - 174

Andrejiova, M.; Kralikova, R.; Wessely, E.; Sokolova, H. (2012). Assesment of the Microclimate in the Work Environment, Chapter 42 in DAAAM International Scientific Book 2012, pp. 509-516, B. Katalinic (Ed.), Published by DAAAM International, ISBN 978-3-901509-86-5, ISSN 1726-9687, Vienna, Austria, Doi: 10.2507/daaam.scibook.2012.42

Garg, A.; Hegmann, K.; Kapellush, J. (2006), Short-cycle overhead work and shoulder girdle muscle fatigue. International Journal of Industrial Ergonomics, Vol. 36, No. 6, pp. $581-597$

Grieve, J. \& Dickersond, C. (2008). Overhead work: identification of evidence based exposure guidelines. Occupational Ergonomics, Vol. 8, no. 1, pp. 53 - 66 Harcombe, H.; McBride, D.; Derrett, S. \& Gray, A. (2009). Prevalence and impact of musculoskeletal disorders in New Zealand nurse, postal workers and office workers. Australian and New Zealand journal of public health, Vol. 33, pp. 437-441

Nussbaum, M.; Clark, L.; Lanza, M. \& Rice, K. (2001). Fatigue and endurance limits during intermittent overhead work. American Industrial Hygiene Association Journal, Vol. 62, No. 4, pp. $446-456$

Polajnar, A.; Leber, M. \& Vujica Herzog, N. (2010). Muscular-skeletal diseases require scientifically designed sewing workstations. Journal of Mechanical Engineering, Vol. 56, No. 1, pp. 31-40

Rosecrance, J.; Rodgers, G. \& Merlino, L, (2006). Low back pain and musculoskeletal symptoms among Kansas Farmers. American Journal of Industrial Medicine, Vol. 47, No. 7, pp. 547-556

Spyropoulus, E.; Chroni, E.; Katsakiori, P. \& Athanassiou, G. (2013). A quantitative approach to assess upper limb fatigue in the work field. Occupational Ergonomics, Vol. 11, pp. 45-57

Warming, S.; Precht, D. M.; Suadicani, P. \& Ebehoj, N. E. (2009). Musculoskeletal complaints among nurses related to patient handling tasks and psychosocial factorsbased on logbook registration. Applied Ergonomics, Vol. 40, pp. 569-578 